\title{
IDENTIFIKASI PENCEMARAN AIR PERMUKAAN SUNGAI BY PASS KOTA PADANG DENGAN METODE SUSEPTIBILITAS MAGNET
}

\author{
Dwi Puryanti, Rizka Pramita Sari \\ Jurusan Fisika, Fakultas Matematika dan Ilmu Pengetahuan Alam, \\ Universitas Andalas, Padang, Sumatera Barat, Indonesia. \\ dwipuryanti@yahoo.co.id
}

\begin{abstract}
ABSTRAK
Sampel air permukaan pada penelitian ini diambil di sekitar kawasan Sungai By Pass Kota Padang. Pengukuran susebtibilitas magnet sampel dilakukan dengan menggunakan Bartington Magnetic Susceptibility sensor model MS2 dengan dual frequency sensor model MS2B. Analisis unsur logam berat yang terkandung dalam air permukaan dilakukan dengan menggunakan Atomic Absorbtion Spektrofotometry, AAS (Analytica Jena Specord 200) atau disebut juga dengan Spektrofotometri Serapan Atom (SSA). Hasil pengukuran susebtibilitas magnetik menunjukkan bahwa nilai rata-rata suseptibilitas sampel sebelum sumber polutan utama adalah berkisar dari $1,08 \times 10^{-5} \mathrm{SI}$ hingga $-0,76 \times 10^{-5} \mathrm{SI}$ dan nilai susebtibilitas sesudah sumber polutan utama adalah berkisar dari $-1,60 \times 10^{-5}$ SI hingga $-0,74 \times 10^{-5}$ SI. Hasil pengukuran Atomic Absorbtion Spektrofotometry menunjukkan bahwa kandungan logam berat Fe yang terdapat di perairan adalah $0,1304 \mathrm{ppm}$.
\end{abstract}

Kata kunci: Pencemaran air permukaan, suseptibilitas magnet, logam berat $(\mathrm{Fe})$

\begin{abstract}
Surface water samples in this study was taken around the area of river bypass, Padang. Magnetic susceptibility measurements were conducted using Bartington MS2 Magnetic Susceptibility sensor models with dual frequency sensor MS2B models. Analysis of heavy metals contained in the surface water is done using Atomic Absorbtion Spektrofotometry (AAS) (Analytica Jena Specord 200). Magnetic susceptibility measurement results show that the average value of the sample prior to susceptibility is a major source of pollutants ranges from $-1.08 \times 10^{-5} \mathrm{SI}$ to $0.76 \times 10^{-5} \mathrm{SI}$ and susebtibilitas value after the main pollutant source is in the range of $-1.60 \times 10^{-5} \mathrm{SI}$ to $-0.74 \times 10^{-5}$ SI. Spektrofotometry Atomic Absorption measurement results indicate that the Fe content of heavy metals contained in water is $0.1304 \mathrm{ppm}$.
\end{abstract}

Keywords: Pollution of surface water, magnetic susceptibility, heavy metals $(\mathrm{Fe})$

\section{PENDAhuluan}

Pencemaran air adalah suatu perubahan keadaan di suatu tempat penampungan air seperti danau, sungai, lautan dan air tanah akibat aktivitas manusia. Perubahan keadaan tersebut dapat terjadi karena masuknya zat, energi atau komponen lain ke dalam air sehingga kualitas dari air tersebut turun hingga batas tertentu yang menyebabkan air tidak dapat dimanfaatkan sebagaimana mestinya. Untuk menentukan suatu sumber air apakah tercemar atau tidak terkadang cukup sulit. Hal ini berkaitan dengan banyaknya variabel yang harus ditentukan seperti BOD, COD, PTT, Krom (keseluruhan), minyak dan lemak, sulfida, nitrogen total dan $\mathrm{pH}$ (Notoatmojo, 1997). 
Sungai yang dinamakan Sungai By Pass terletak di Kelurahan Batung Tabang, Kecamatan Lubuk Begalung, Kota Padang. Sebagian besar pemanfaatan Sungai By Pass adalah untuk keperluan rumah tangga seperti mandi dan mencuci. Karena kegunaan sungai yang begitu penting bagi masyarakat setempat maka perlu kiranya diketahui kualitas air permukaan dari sungai tersebut.

Dari survey lapangan yang telah dilakukan di sekitar sungai terdapat kegiatan industri minyak sawit dan pabrik karet. Dalam operasinya industri-industri tersebut menghasilkan limbah yang salah satunya adalah limbah cair yang pembuangan akhirnya bermuara ke sungai tersebut. Meskipun limbah cair yang dibuang sudah diolah oleh industri atau pabrik yang bersangkutan, masih ada kemungkinan bahan pencemar akan mencemari sungai. Hal ini dapat diketahui sementara dari perubahan keadaan air yang terjadi pada waktu industri-industri tersebut melakukan kegiatan pembuangan limbah. Limbah buangan tersebut dikhawatirkan mengandung bahan-bahan sisa yang bersifat toksit atau racun yang merupakan bahan buangan dari limbah industri karet dan limbah minyak sawit. Komponen limbah buangan industri yang mengandung unsur atau senyawa logam berat juga merupakan racun dengan daya racun tinggi (Palar, 1994). Salah satu logam berat yang di duga mencemari perairan tersebut adalah logam $\mathrm{Fe}$ karena adanya penambangan pasir besi di sekitar kawasan sungai. Pencemaran suatu perairan oleh logam berat menyebabkan nilai suseptibilitas air yaitu -0,90 x 10-5 SI (Hunt, 1991) akan berubah akibat kehadiran logam tersebut.

\section{METODE PENELITIAN}

Sampel yang digunakan pada kajian ini diambil dari air permukaan yang berada di sekitar Sungai By Pass Padang. Selanjutnya dilakukan pengukuran suseptibilitas magnet terhadap air tersebut di laboratorium Fisika Bumi Fakultas Matematika dan Ilmu Pengetahuan Alam Universitas Andalas untuk memastikan apakah air permukaan tersebut telah tercemar. Setelah itu dilakukan pengujian unsur dan kandungan logam berat $(\mathrm{Fe})$ yang terdapat dalam air permukaan di Sungai By Pass, Padang. Posisi masing-masing titik pengambilan sampel diperlihatkan pada Gambar 1.

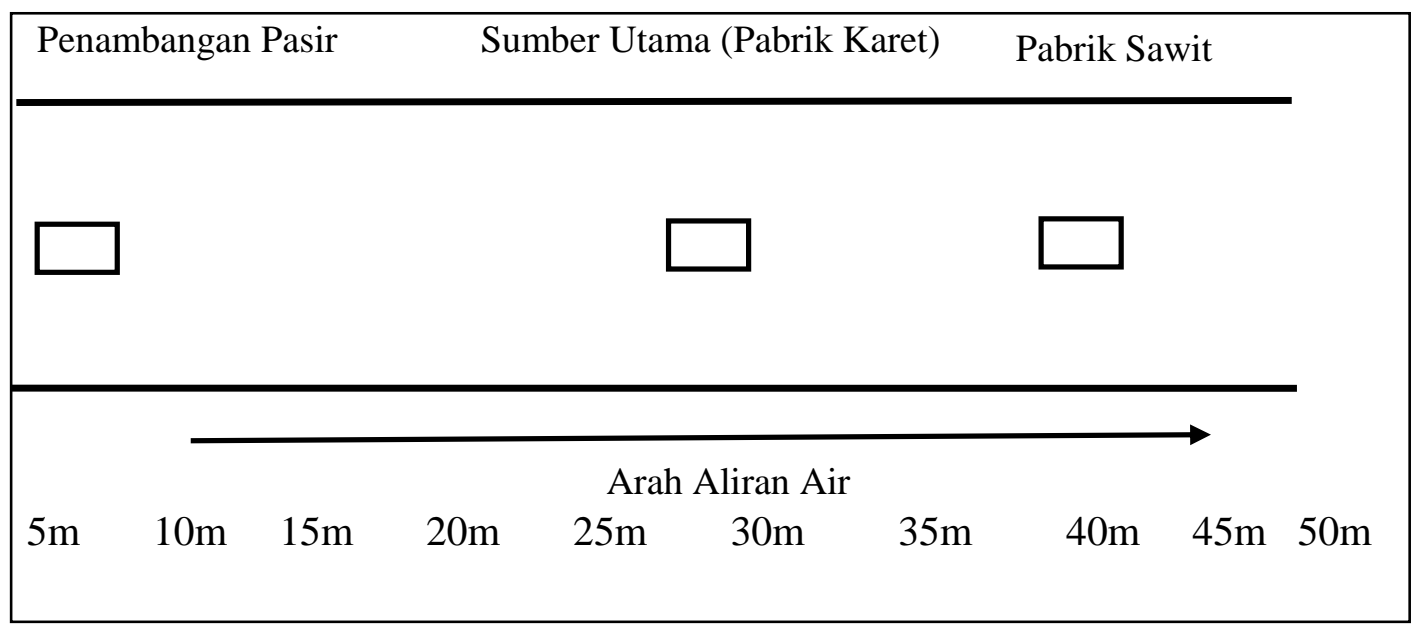

Gambar 1. Posisi setiap titik pengambilan sampel pada Sungai By Pass 


\section{ISSN 1979-4657}

Pengukuran suseptibilitas magnetik dilakukan menggunakan Bartington Magnetic Susceptibility sensor model MS2 dengan dual frequency sensor model MS2B. Pengukuran suseptibilitas ini dilakukan untuk 10 sampel, setiap sampel dilakukan pengukuran sebanyak 5 kali. Untuk menganalisa unsur logam berat yang terkandung dalam air permukaan digunakan Spektrofotometri Serapan Atom (SSA) atau Atomic Absorbtion Spektrofotometry, AAS (Analytica Jena Specord 200). Diagram alir tata laksana penelitian diberikan pada Gambar 2.

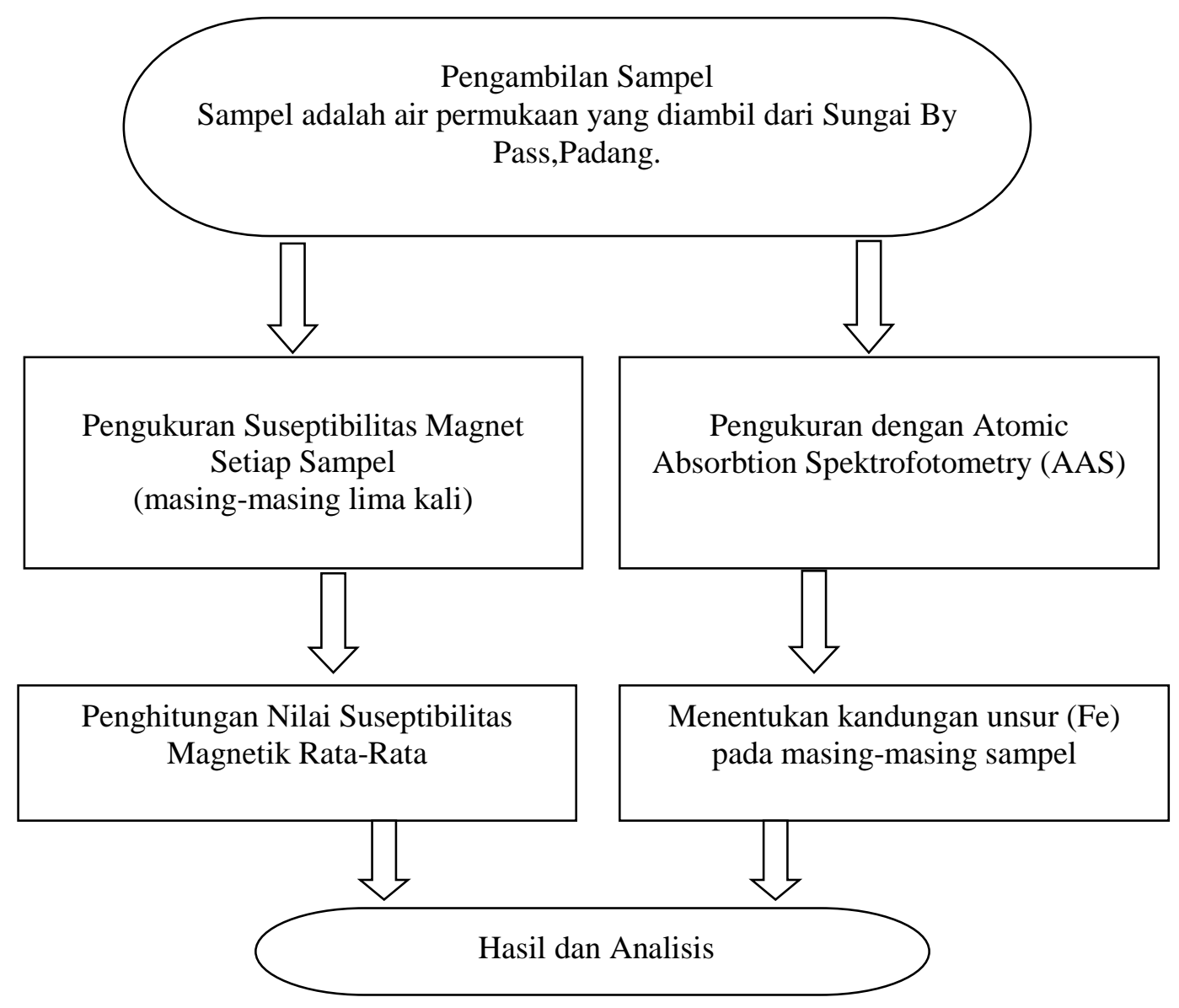

Gambar 2. Diagram alir tata laksana penelitian

\section{HASIL DAN PEMBAHASAN}

Nilai rata-rata suseptibilitas magnetik, konsentrasi kandungan Fe, jarak dan koordinat pada setiap titik lokasi pengambilan sampel pada Sungai By Pass diperlihatkan pada Tabel 1. 
Tabel 1. Nilai rata-rata suseptibilitas dan konsentrasi kandungan Fe sampel di setiap titik lokasi pengambilan data.

\begin{tabular}{|c|c|c|c|c|c|}
\hline $\begin{array}{c}\text { Titik } \\
\text { Lokasi }\end{array}$ & $\begin{array}{c}\text { Lintang } \\
\text { Selatan } \\
\left(\mathrm{LS}^{\circ}\right)\end{array}$ & $\begin{array}{c}\text { Bujur } \\
\text { Timur } \\
\left(\mathrm{BT}^{\circ}\right)\end{array}$ & $\begin{array}{c}\text { Jarak } \\
(\mathrm{m})\end{array}$ & $\begin{array}{c}\text { Suseptibilitas } \\
\left(\times 10^{-5}\right)\end{array}$ & $\begin{array}{c}\text { Konsentrasi } \\
(\mathrm{ppm}) \mathrm{mg} / \mathrm{L}\end{array}$ \\
\hline 1. & 0,96055 & 100,40269 & 5 & $-0,80$ & 0,0325 \\
\hline 2. & 0,96054 & 100,40268 & 10 & $-0,76$ & $-0,0215$ \\
\hline 3. & 0,96064 & 100,40279 & 15 & $-0,78$ & $-0,1127$ \\
\hline 4. & 0,96063 & 100,40279 & 20 & $-1,08$ & $-0,1415$ \\
\hline 5. & 0,96060 & 100,40292 & 25 & $-0,98$ & $-0,1417$ \\
\hline 6 & 0,95953 & 100,40451 & 30 & $-0,74$ & 0,0490 \\
\hline 7 & 0,95954 & 100,40451 & 35 & $-1,48$ & 0,1298 \\
\hline 8 & 0,95955 & 100,40427 & 40 & $-0,92$ & 0,1304 \\
\hline 9 & 0,95956 & 100,40427 & 45 & $-1,60$ & 0,0055 \\
\hline 10 & 0,96059 & 100,40292 & 50 & $-1,46$ & 0,0018 \\
\hline
\end{tabular}

Dari Tabel 1 dapat dilihat bahwa nilai suseptibilitas sampel yang diambil dari Sungai bervariasi. Nilai suseptibilitas yang semakin negatif menunjukkan sifat diamagnetik yang lebih dominan (Griffiths, 1989). Berdasarkan teori momen dipol magnet, sifat kemagnetan bahan ditimbulkan oleh gerak orbital elektron. Pada bahan diamagnetik, setiap atom mempunyai elektron orbital dan hampir semua spin elektron berpasangan, sehingga bahan ini tidak menarik garis gaya (Griffiths, 1989). Dengan demikian, bahan diamagnetik memiliki permeabilitas $\mu<\mu_{0}$, sedangkan bahan feromagnetik memiliki permeabilitas $\mu_{0}>0$ serta suseptibilitas $\chi_{\mathrm{m}}>0$ (Griffiths, 1989).

Pada titik 1 nilai seseptibilitas sampel adalah $-0,8 \times 10^{-5}$ SI yang menunjukkan bahwa nilai ini melebihi nilai suseptibilitas air normal yaitu $-0,9 \times 10^{-5}$ SI sehingga pada titik ini dapat dikatakan terdapat bahan mencemar yang dideteksi berupa logam yang mencemari sungai. Pada titik ini konsentrasi $\mathrm{Fe}$ yang terdeteksi adalah 0,0325 ppm. Hal ini berhubungan dengan terdapatnya penambangan pasir yang diketahui mengandung logam Fe yang berada di sekitar kawasan sungai, dimana logam Fe termasuk salah satu logam berat yang mudah mengendap. Namun pada jarak $10 \mathrm{~m}$ nilai suseptibilitas naik $-0,76 \mathrm{x}$ $10^{-5}$ SI. Walaupun logam Fe termasuk bahan feromagnetik yaitu bahan yang memiliki spin elektron tidak berpasangan, dimana masing-masing spin elektron yang tidak berpasangan yang dapat menimbulkan medan magnet, tetapi karena konsentrasinya yang sangat sedikit terdapat di perairan maka suseptibilitas yang dihasilkan masih dalam kategori diamagnetik. Pada titik 3 dan titik 4 nilai seseptibilitas semakin kecil, yang menunjukkan bahwa konsentrasi Fe yang terdapat di perairan semakin kecil. Hal ini terjadi karena pengaruh aliran Sungai dengan kecepatan jatuh partikel semakin jauh dari sumber maka konsentrasi logam semakin berkurang karena kecepatan jatuh butiran ditentukan oleh hambatan aliran.

Nilai suseptibilitas pada titik 6 kembali naik karena pada titik ini terdapat sumber utama pencemar yaitu pabrik karet yang menghasilkan limbah logam. Walaupun nilai suseptibilitas sampel naik, yang juga dinyatakan oleh kenaikan nilai konsentrasi Fe, tetapi keadaan sampel masih bersifat diamagnetik karena nilai suseptibilitas yang dihasilkan masih negatif. Hal ini menyatakan bahwa bahan pencemar yang berupa logam yang dikeluarkan oleh pabrik karet konsentrasinya adalah kecil. Pada titik 7 nilai suseptibilitas menurun sedangkan nilai konsentrasi kandungan $\mathrm{Fe}$ meningkat. Keadaan tersebut kemungkinan disebabkan metode suseptibilitas magnetik tidak dapat mengidentifikasi 
bahan yang terkontaminasi oleh bahan lain akibat ada paduan polaritas dalam cairan. Pada kondisi polaritas stabil (normal) maka suseptibilitas magnet tidak dapat dapat mendeteksi logam.

Pada titik 8 nilai suseptibilitas kembali naik dan juga nilai konsentrasi kandungan logam Fe juga naik karena disekitar titik ini terdapat sumber pencemar lain yaitu pabrik kelapa sawit. Selanjutnya nilai suseptibilitas dan nilai konsentrasi kandungan Fe menurun pada titik 9 dan titik 10 karena jarak yang semakin menjauh dari sumber pencemar.

\section{KESIMPULAN DAN SARAN}

Hasil penelitian menunjukkan nilai rata-rata suseptibilitas magnet sampel air permukaan Sungai By Pass Kota Padang adalah berkisar dari -1,6 x $10^{-5} \mathrm{SI}$ hingga $-0,74 \times 10^{-5} \mathrm{SI}$.

Hasil pengukuran dengan Atomic Absorption Spectrophotometry (AAS), diperoleh nilai konsentrasi kandungan logam berat $\mathrm{Fe}$ pada air permukaan di Sungai By Pass Kota Padang mempunyai nilai maksimum $0,13037 \mathrm{ppm}$. Nilai ini masih dalam batas yang diperbolehkan sesuai dengan surat Keputusan Menteri Negara Kependudukan dan Lingkungan Hidup, KepMen LH No. 51 tahun 2004.

Posisi titik tempat pengambilan sampel mempengaruhi besar kecilnya zat pencemar yang terbawa oleh suatu aliran.

\section{DAFTAR PUSTAKA}

1. Griffiths, David J., 1989: Introduction to Electrodynamics, Prentice Hall, Englewood Cliffs, New Jersey

2. Hunt, C. P. 1991. Handbook from The Environmental magnetism Workshop. Minneapolis: University of Minnesota.

3. Notoatmojo, Soekidjo. 1997. Ilmu Kesehatan Masyarakat. Rineka Cipta: Jakarta.

4. Palar, H.1994. Pencemaran dan Toksikan Logam Berat. Jakarta: Penerbit Rineka Cipta. 